\title{
CARACTERIZAÇÃO DA PIRITA QUANTO A DANOS AMBIENTAIS, UTILIZANDO PARÂMETROS FÍSICO- QUÍMICOS E BIOENSAIO
}

\author{
J. B. NUERNBERG ${ }^{1}$, K. MADEIRA ${ }^{2}$, M. L. ALANO ${ }^{3}$, M. PETERSON ${ }^{1,4}$, M. da C. \\ MARTINS $^{5}$
}

${ }^{1}$ Universidade do Extremo Sul Catarinense, Laboratório de Reatores e Processos Industriais

${ }^{2}$ Universidade do Extremo Sul Catarinense, Laboratório de Epidemiologia

${ }^{3}$ Centro de Educação Profissional Abílio Paulo

${ }^{4}$ Universidade do Extremo Sul Catarinense, Departamento Engenharia Química

${ }^{5}$ Universidade do Extremo Sul Catarinense, Laboratório de Ensino em Ciência

E-mail para contato: julia-b-n@ hotmail.com

\begin{abstract}
RESUMO - O presente trabalho teve como objetivo avaliar a toxicidade da pirita, utilizando parâmetros físico-químicos e bioensaio. As análises físico-químicas sugerem a redução da qualidade da água quando exposta a pirita, com diminuição de $\mathrm{pH}$ e elevação da concentração dos metais ferro, alumínio e manganês. Comparando os resultados a Resolução $n^{\circ} 357$ do CONAMA, as águas expostas a pirita apresentam-se comprometidas. A pirita provocou significativa fitotoxicidade em Allium cepa $L$. Dessa forma, a pirita pode ser considerada perigosa no ponto de vista ambiental decorrente da composição por metais pesados.
\end{abstract}

\section{INTRODUÇÃO}

A mineração de carvão é uma das principais atividades econômica na região sul de Santa Catarina. No entanto, a região é detentoras das maiores concentrações de rejeito piritoso do estado, devido a atividade extrativa desordenada. Entre os contaminantes encontra-se solos inférteis, atmosfera contaminada por enxofre, e as drenagens ácidas de mina, caracterizada pela elevada concentração de metais como alumínio, ferro, manganês, sulfato e baixo pH.

$\mathrm{O}$ alto teor de pirita contido nos rejeitos piora ainda mais o problema, uma vez que vem lixiviando durante anos, contaminando a maior parte das bacias hidrográficas e reservas subterrâneas de água da região sul de Santa Catarina (Peterson, 2009). Além disso, o acúmulo desordenado de compostos químicos resultará num dano biológico ao sistema aquático, ocasionando alterações e até a morte da biota exposta, cujo metabolismo não é capaz de tolerar tais concentrações (Inamps. 1988; Crepald, 1992). Dessa forma, o monitoramento da qualidade da água é de grande relevância para conservação da qualidade ambiental.

Esse trabalho tem como objetivo avaliar o potencial tóxico da pirita, e para isso foram utilizados parâmetros físico-químicos, tais como $\mathrm{pH}$ e concentração dos metais alumínio, ferro e manganês. Utilizou-se como referência a Resolução n ${ }^{\circ} 357$ de 17 de março de 2005 do Conselho Nacional do Meio Ambiente (CONAMA), que dispõe sobre a classificação dos 
corpos de água e diretrizes ambientais para o seu enquadramento, bem como estabelece as condições e padrões de lançamento de efluentes (CONAMA, 2005).

Também realizou-se bioensaio, no intuito de avaliar a toxicidade no organismo. O Allium cepa $L$. (cebola) foi utilizada para avaliação da fitotoxicidade. Esse bioindicador tem sido recomendado para análises de efluentes devido a sua elevada sensibilidade, baixo custo, rapidez, facilidade de manipulação e da utilização de amostras sem tratamento prévio (Leme e Marin-Morales, 2009).

\section{MATERIAIS E MÉTODOS}

\subsection{Análises Físico-químicas}

Uma amostra de pirita foi coletada em uma carbonífera na região sul de Santa Catarina/Brasil. A amostra de pirita foi lacrada e armazenada a temperatura ambiente. Decorreram-se quatro meses até a preparação de uma única concentração contendo $18 \mathrm{~g}$ de pirita para $1 \mathrm{~L}$ de água deionizada. Após sete dias de reação da pirita em água deionizada realizou-se as análises físico-químicas.

A análise de $\mathrm{pH}$ foi realizada por potenciometria (pHmetro 905 TITRANDO METROHN), e a concentração dos metais alumínio, ferro e manganês foi determinado por Espectrofotometria de Absorção Atômica em Chama (espectrômetro AGILENT 700/720 ICPOES). Os parâmetros físico-químicos foram realizados em duplicata.

\subsection{Teste de fitotoxicidade Allium cepa $L$.}

Para avaliação da fitotoxicidade do Allium cepa L. o ensaio foi conduzido de acordo com Fiskejo (1988), com adaptações. Indivíduos de A. cepa tiveram suas raízes cortadas, e os bulbos $(\mathrm{n}=6)$ colocados sobre os tubos Falcon de $55 \mathrm{~mL}$, contento diferentes concentrações de água deionizada e pirita (Figura 1). Para o controle negativo foi utilizado apenas água deionizada. As amostras foram reabastecidas diariamente, e após 7 dias de exposição, à temperatura ambiente e ao abrigo de luz, foi retirado as raízes dos bulbos e determinado o comprimento das raízes, seguida de contagem do número de raízes.

Figura 1 - Disposição do ensaio realizando com Allium cepa $L$.

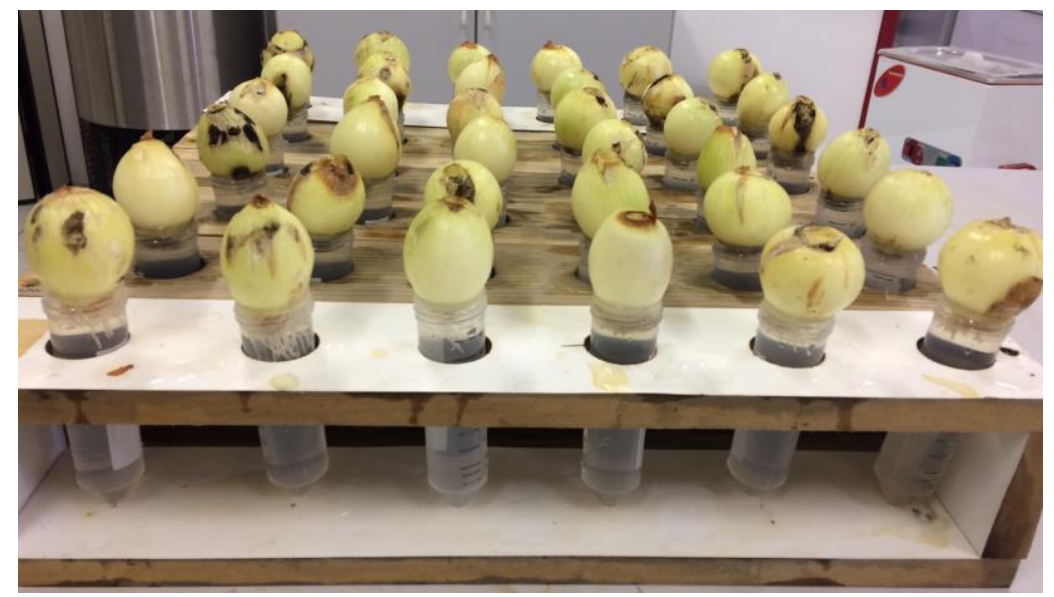


Os dados coletados foram analisados com auxílio do software IBM Statistical Package for the Social Sciencies (SPSS) versão 22.0. As variáveis quantitativas foram expressas por meio de mediana e amplitude (valores mínimo e máximo) e por média e desvio padrão.

Os testes estatísticos foram realizados com um nível de significância $\alpha=0,05$ e, portanto, confiança de $95 \%$. A distribuição dos dados quanto à normalidade foi avaliada por meio da aplicação do teste de Shapiro-Wilk. A investigação da variabilidade das variáveis quantitativas entre as categorias das variáveis qualitativas foi investigada por meio da aplicação do teste de Levene. A comparação da média do tamanho das raízes de cebola entre as diferentes concentrações de pirita foi realizada por meio da aplicação da análise de variância de uma via, ANOVA, seguida do post hoc teste de Games-Howell.

\section{RESULTADOS E DISCUSSÃO}

\subsection{Parâmetros físico-químicos da solução}

Os resultados das análises físico-químicas estão dispostos em tabela (Tabela 1), juntamente com os valores previstos na Resolução $\mathrm{n}^{\circ} 357$ do CONAMA. Os resultados comprovam que a amostra com concentração de $0,1 \mathrm{~g}$ de pirita completo com água deionizada possuía expressiva concentração de ferro, manganês, e pH ácido, em relação a Resolução.

Tabela 1 - Parâmetros físico-químicos da solução de pirita e água deionizada, e os valores previstos na Resolução n ${ }^{\circ} 357$ do CONAMA.

\begin{tabular}{|c|c|c|}
\hline Parâmetros físico-químicos & Solução & Resolução no 357/CONAMA \\
\hline \hline $\mathrm{pH}$ & 3,6 & 5,0 a 9,0 \\
\hline Alumínio $^{\text {(mg.L-1) }}$ & 5,2 & $\mathrm{NP}$ \\
\hline Ferro $^{{ }^{(m g . L-1)}}$ & 18,5 & 15,0 \\
\hline Manganês $^{\text {(mg.L-1) }}$ & 1,8 & 1,0 \\
\hline
\end{tabular}

$\mathrm{NP}=$ Não previsto.

Segundo a Resolução CONAMA (2005), os efluentes de qualquer fonte poluidora poderão ser lançados de forma direta ou indireta na rede hidrográfica somente após a sua remediação e desde que apresentem parâmetros físico-químicos compatíveis com os valores de referência preconizados pela sua normativa e de outros dispositivos legais aplicáveis. Dessa forma, observa-se que o efluente avaliado não está dentro dos padrões estabelecidos em legislação, podendo comprometer o ecossistema por ser potencialmente tóxico.

\subsection{Teste de fitotoxicidade Allium cepa $L$.}

Há evidências de que a concentração de pirita no solo em níveis $0,03,0,05,0,1,0,15$ ou $0,2 \mathrm{~g}$ interfiram de forma significativa no crescimento das raízes de cebola, sendo o tamanho dessas significativamente menor quando comparadas a uma amostra sem concentração $(0 \mathrm{~g})$ desse elemento $(\mathrm{p}<0,001)$. Pode-se observar também, que quando a concentração de pirita foi $0,2 \mathrm{~g}$, não houve crescimento da raiz. A síntese dos resultados obtidos está apresentada por meio da Tabela 2 e da Figura 2. 


\section{Congresso Brasileiro de Engenharia Química \\ em Iniciação Científica \\ UFSCar - São Carlos - SP \\ 16 a 19 de Julho de 2017}

CONGRESSO BRASILEIRO DE ENGENHARIA

Tabela 2 - Tamanho das raízes de Allium cepa L. em diferentes concentrações de pirita (g).

\begin{tabular}{|c|c|c|c|c|}
\hline \multirow{2}{*}{ Concentração de Pirita $(\mathrm{g})$} & \multirow{2}{*}{$\mathrm{N}$} & \multicolumn{2}{|c|}{ Tamanho das raízes (mm) } & \multirow{2}{*}{ Valor-p } \\
\cline { 3 - 4 } & & Média \pm DP & Md (mín-máx) & \multirow{2}{*}{} \\
\hline 0,00 & 6 & $17,87 \pm 1,19^{\mathrm{a}}$ & $17,24(16,99-19,91)$ & $<001^{*}$ \\
\hline 0,03 & 6 & $2,16 \pm 0,21^{\mathrm{b}}$ & $2,18(1,89-2,43)$ & \\
\hline 0,05 & 6 & $2,00 \pm 0,17^{\mathrm{b}}$ & $2,04(1,73-2,18)$ & \\
\hline 0,10 & 6 & $2,05 \pm 0,25^{\mathrm{b}}$ & $2,05(1,77-2,42)$ & \\
\hline 0,15 & 6 & $1,50 \pm 0,26^{\mathrm{b}}$ & $1,50(1,14-1,92)$ & \\
\hline 0,20 & 6 & - & - & \\
\hline
\end{tabular}

* valor obtido após aplicação da análise de variâncias de uma via ANOVA.

a,b Letras distintas representam diferenças estatisticamente significativas após aplicação do teste post hoc de Games-Howell ( $\mathrm{p}<0,001)$.

$\mathrm{DP}=$ desvio padrão; $\mathrm{Md}=$ mediana; mín = valor mínimo observado máx = valor máximo observado.

Figura 2 - Comprimento das raízes de Allium cepa L. em diferentes concentrações de pirita (g).

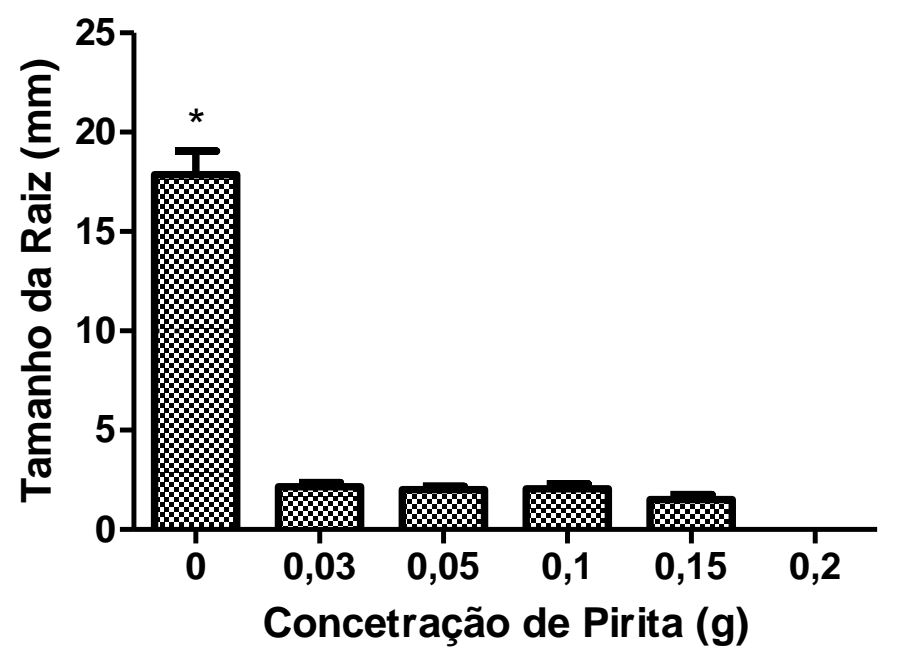

* valor obtido após aplicação da análise de variâncias de uma via ANOVA seguido do post hoc teste de GamesHowell $(\mathrm{p}<0,001)$.

Sugere-se que este efeito fitotóxico estaria relacionado à capacidade destes compostos serem acumulados pela planta e interagirem com sítios específicos localizados na parede celular, na membrana plasmática e no núcleo celular. Como consequência, poderiam ser desencadeadas diversas alterações fisiológicas, bioquímicas e moleculares na célula.

Outros estudos também podem ser encontrados na literatura, como o de Geremias et al. (2009), onde constataram que efluentes da mineração de carvão a uma baixa concentração $(9,21 \%)$ foram capazes de inibir em $50 \%$ o crescimento de raízes de a exposição de A. cepa exposta aos mesmos, sendo sugerido que o efeito fitotóxico estaria associado aos baixos valores de $\mathrm{pH}$ e expressiva concentração de metais como ferro, alumínio, manganês, zinco e chumbo. 


\section{CONCLUSÃO}

Diante dos resultados obtidos, pode-se concluir que a pirita em água apresentou expressiva toxicidade, pelo baixo valor de $\mathrm{pH}$ e elevada concentração de ferro e manganês, comparados a legislação, previsto pela Resolução $n^{\circ} 357$ do CONAMA, além da concentração de alumínio. Confirmou-se elevado efeito fitotóxico da pirita em Allium cepa L. Dessa forma, foi constatado o alto potencial tóxico da pirita para o ecossistema, havendo a necessidade do compromisso das empresas carboníferas em dispor a pirita de forma correta no solo, com proteção e cobertura adequada, evitando a infiltração nos lençóis freáticos e transporte desse resíduo para os rios.

\section{REFERÊNCIAS}

CREPALDI, M. Degradação ambiental pela extração do carvão em Siderópolis, SC que pensam os alunos. Criciúma, SC: FUCRI, 1992. 42 p.

CONAMA. Conselho Nacional do Meio Ambiente. Resolução CONAMA n. 357, de 17 de março de 2005. Dispõe sobre a classificação dos corpos de água e diretrizes ambientais para o seu enquadramento, bem como estabelece as condições e padrões de lançamento de efluentes, e dá outras providências. Ministério do Meio Ambiente. Brasília, 2005.

FISKESJÖ, G. The Allium test - an alternative in environmental studies: the relative toxicity of metal ions. Mutation Research, v.197, n.2, p.243 - 260, 1988.

GEREMIAS, R. Utilização de rejeito de mineração de carvão como adsorvente para redução da acidez e remoção de íons de metais em drenagem ácida de mina de carvão. 2009, 121 p. Tese (Doutorado em Química), Programa de Pós Graduação em Química da Universidade Federal de Santa Catarina, Florianópolis.

INAMPS - Instituto Nacional de Previdência Social. Impacto do processo produtivo da extração do carvão mineral na saúde humana e ambiental no município de Criciúma. Criciúma, SC: 1988.158 p.

LEME, D.M.; MARIN-MORALES, M.A. Allium cepa test in environmental monitoring: A review on its application. Mutation Research, Amsterdam, v. 682, n. 1, p. 71-81, 2009.

PETERSON, M. Produção de sulfato ferroso a partir da pirita: desenvolvimento sustentável. 2008. 127 f. Tese (Pós-Graduação em Engenharia Química). Universidade Federal de Santa Catarina, Florianópolis. 